\title{
How innate is locomotion in precocial animals? A study on the early development of spatio-temporal gait variables and gait symmetry in piglets
}

\author{
Charlotte Vanden Hole ${ }^{1, *}$, Jana Goyens ${ }^{2}$, Sara Prims ${ }^{1}$, Erik Fransen ${ }^{3}$, Miriam Ayuso Hernando ${ }^{1}$, \\ Steven Van Cruchten ${ }^{1}$, Peter Aerts ${ }^{2}$ and Chris Van Ginneken ${ }^{1}$
}

\begin{abstract}
Locomotion is one of the most important ecological functions in animals. Precocial animals, such as pigs, are capable of independent locomotion shortly after birth. This raises the question whether coordinated movement patterns and the underlying muscular control in these animals is fully innate or whether there still exists a rapid maturation. We addressed this question by studying gait development in neonatal pigs through the analysis of spatio-temporal gait characteristics during locomotion at self-selected speed. To this end, we made video recordings of piglets walking along a corridor at several time points (from $0 \mathrm{~h}$ to $96 \mathrm{~h}$ ). After digitization of the footfalls, we analysed self-selected speed and spatio-temporal characteristics (e.g. stride and step lengths, stride frequency and duty factor) to study dynamic similarity, intralimb coordination and interlimb coordination. To assess the variability of the gait pattern, left-right asymmetry was studied. To distinguish neuromotor maturation from effects caused by growth, both absolute and normalized data (according to the dynamic similarity concept) were included in the analysis. All normalized spatiotemporal variables reached stable values within $4 \mathrm{~h}$ of birth, with most of them showing little change after the age of $2 \mathrm{~h}$. Most asymmetry indices showed stable values, hovering around $10 \%$, within $8 \mathrm{~h}$ of birth. These results indicate that coordinated movement patterns are not entirely innate, but that a rapid neuromotor maturation, potentially also the result of the rearrangement or recombination of existing motor modules, takes place in these precocial animals.
\end{abstract}

KEY WORDS: Locomotion, Sus scrofa, Spatio-temporal gait characteristics, Neuromotor maturation

\section{INTRODUCTION}

Without doubt, locomotion can be considered a key ecological function (e.g. Bertram, 2016). It is important for, among others, finding food, mates and shelter, avoiding predators, and migration. Legged terrestrial locomotion implies cyclical movement patterns characterized by specific interlimb and intralimb coordination patterns (e.g. Alexander, 2003; Bertram, 2016; Biewener, 2003). These patterns emerge from the interaction and feedback between the intrinsic mechanics of the musculoskeletal system and the

${ }^{1}$ Laboratory of Applied Veterinary Morphology, Department of Veterinary Sciences, Faculty of Biomedical, Pharmaceutical and Veterinary Sciences, University of Antwerp, 2610 Wilrijk, Belgium. ${ }^{2}$ Laboratory of Functional Morphology, Department of Biology, Faculty of Sciences, University of Antwerp, 2610 Wilrijk, Belgium.

${ }^{3}$ StatUa Center for Statistics, University of Antwerp, 2000 Antwerp, Belgium.

*Author for correspondence (charlotte.vandenhole@uantwerpen.be)

(iD) C.V., 0000-0001-5341-6518

Received 5 February 2017; Accepted 17 May 2017 environment on the one hand and neurological control on the other (e.g. Latash, 2008; Nishikawa et al., 2007). The latter is initiated at the cortical level and signals descend (via lower brain centres) the spinal cord to activate coupled spinal neural networks (central pattern generators, CPGs), which transform the command into coordinated muscle-tendon actions distributed over the limbs and joints (Grillner, 2011; Grillner et al., 2000; Lacquaniti et al., 2012b; Latash, 2008; Orlovsky et al., 1999).

It has been argued that the muscle activity generating the coordinated output at the level of the limb muscle-tendon system is actually accounted for by a combination of a limited number of weighted basic activation patterns. These originate from locomotor modules, which are in turn part of the neuronal networks of the spinal cord (Cappellini et al., 2006; Dominici et al., 2011; Ivanenko et al., 2004b, 2005, 2006; Lacquaniti et al., 2012a,b; Neptune et al., 2009). In humans, two of these basic patterns (essential for support during stance and to drive the limb during swing) are already present in neonates (Dominici et al., 2011; Lacquaniti et al., 2012b). Neonatal rats possess the same two basic patterns (Dominici et al., 2011; Lacquaniti et al., 2012b), and it is suggested that this most probably holds true for other animals as well (Dominici et al., 2011; Grillner, 2011). In some species (such as humans), further development of gait (i.e. inclusion of the remaining basic patterns) takes months to years. In the framework of the 'weighted patterned control', this implies that the additional basic patterns require time to develop and mature.

Despite evidence for evolutionarily conserved timing of locomotor development in mammals, effective postnatal time to onset of independent walking may differ greatly (Garwicz et al., 2009). Humans, rats and mice are altricial and, as such, they are incapable of independent locomotion immediately after birth. But what about precocial mammals (e.g. most ungulates), which are able to move about soon after birth? In the case of wildebeest, for instance, neonates follow the herd in less than $1 \mathrm{~h}$ (Pennycuick, 1975; Estes and Estes, 1979). Are the coordinated movement patterns and the underlying muscular control in precocial mammals fully innate or does there still exist (a rapid) maturation? We wanted to address this general question by studying early gait development (between birth and the age of $96 \mathrm{~h}$ ) of neonatal pigs (Sus scrofa). Within a matter of minutes, healthy newborn pigs are able to stand up, after which they quickly (within hours) develop full locomotor capacity (Graves, 1984; Pond and Mersmann, 2001).

Here, we focused on the spatio-temporal characteristics (or steptime variables) of the limb movements of piglets during voluntary locomotion at a self-selected speed ( $u$; for an overview of all variables see Table 1). According to the 'hybrid' dynamic pattern approach to locomotion (Latash, 2008), these characteristics can be considered the most basic collective output emerging from the entire 
Table 1. Summary of all used variables (abbreviations, definitions and formulas), including normalization procedure

\begin{tabular}{|c|c|c|c|c|}
\hline Variable & Abbreviation & Definition & Formula & Normalization \\
\hline Centre of mass & COM & - & - & - \\
\hline $\begin{array}{l}\text { Gravitational } \\
\text { acceleration }\end{array}$ & $g$ & - & - & - \\
\hline $\begin{array}{l}\text { Functional leg } \\
\text { height }\end{array}$ & $H$ & $\begin{array}{l}\text { Distance between the most distal part of the distal phalanx and the tail } \\
\text { base. }\end{array}$ & & \\
\hline $\begin{array}{l}\text { Self-selected } \\
\text { speed }\end{array}$ & $u$ & $\begin{array}{l}\text { The movement of the COM during one cycle divided by the duration of the } \\
\text { cycle. Animals are able to move in an unrestrained, voluntary way. }\end{array}$ & $f l_{\text {stride }}$ & $\frac{u}{\sqrt{H g}}$ \\
\hline Stride frequency & $f$ & Inverse of the period between two consecutive footfalls of a particular leg. & $\frac{u}{I_{\text {stride }}}$ & $f \sqrt{H \boldsymbol{g}}$ \\
\hline Stride length & $I_{\text {stride }}$ & The forward movement during one stride or cycle. & & $\frac{I_{\text {stride }}}{H}$ \\
\hline Stance duration & $t_{\mathrm{s}}$ & The period of contact between a limb and the ground. & - & $\frac{t_{\mathrm{st}}}{\sqrt{H / g}}$ \\
\hline Swing duration & $t_{\mathrm{sw}}$ & The period of limb flight. & - & $\frac{t_{\mathrm{sw}}}{\sqrt{H / g}}$ \\
\hline Step length & $I_{\text {step }}$ & The movement of the centre of mass during one step (stance phase only). & - & $\underline{I_{\text {step }}}$ \\
\hline Duty factor & df & The fraction of the cycle for which the limb is in contact with the ground. & - & $\underline{H}$ \\
\hline Front lag & f-lag & $\begin{array}{l}\text { The time lag between the two front footfalls as a function of the average } \\
\text { cycle duration of the front leg pair }\left(d_{\text {front }}\right) \text {. Adapted from Abourachid } \\
(2003) \text {. }\end{array}$ & $\frac{f-l a g}{d_{\text {front }}}$ & - \\
\hline Hind lag & h-lag & $\begin{array}{l}\text { The time lag between the two hind footfalls as a function of the average } \\
\text { cycle duration of the hind leg pair }\left(d_{\text {hind }}\right) \text {. Adapted from Abourachid } \\
(2003) \text {. }\end{array}$ & $\frac{\mathrm{h}-\mathrm{lag}}{d_{\text {hind }}}$ & - \\
\hline Pair lag & p-lag & $\begin{array}{l}\text { The time lag between the two ipsilateral footfalls as a function of the } \\
\text { average cycle duration of the ipsilateral leg pair }\left(d_{i p s i}\right) \text {. Adapted from } \\
\text { Abourachid (2003). }\end{array}$ & $\frac{p-l a g}{d_{\text {ipsi }}}$ & \\
\hline Diagonal lag & d-lag & $\begin{array}{l}\text { The time lag between the two diagonal footfalls as a function of the } \\
\text { average cycle duration of the diagonal leg pair }\left(d_{\mathrm{dia}}\right) \text {. Adapted from } \\
\text { Abourachid (2003). }\end{array}$ & $\frac{\mathrm{d}-\mathrm{lag}}{d_{\mathrm{dia}}}$ & - \\
\hline $\begin{array}{l}\text { Al stride } \\
\text { frequency }\end{array}$ & $\mathrm{Al}_{f}$ & $\begin{array}{l}\text { Asymmetry index of stride frequency. Adapted from Robinson et al. } \\
\text { (1987). }\end{array}$ & $\frac{\left(f_{\mathrm{R}}-f_{\mathrm{L}}\right)}{0.5\left(f_{\mathrm{R}}-f_{\mathrm{L}}\right)} 100 \%$ & \\
\hline Al stride length & $\mathrm{Al}_{\text {stride }}$ & Asymmetry index of stride length. Adapted from Robinson et al. (1987). & $\frac{\left(I_{\text {stride }, \mathrm{R}}-I_{\text {stride } \mathrm{L}}\right)}{0.5\left(I_{\text {stride }, \mathrm{R}}-I_{\text {stride } \mathrm{L}}\right)} 100 \%$ & - \\
\hline Al stance duration & $\mathrm{Al}_{t_{\mathrm{st}}}$ & Asymmetry index of stance duration. Adapted from Robinson et al. (1987). & $\frac{\left(t_{\mathrm{st}, \mathrm{R}}-t_{\mathrm{st}, \mathrm{L}}\right)}{0.5\left(t_{\mathrm{st}, \mathrm{R}}-t_{\mathrm{st}, \mathrm{L}}\right)} 100 \%$ & - \\
\hline Al swing duration & $\mathrm{Al}_{t_{\mathrm{sw}}}$ & Asymmetry index of swing duration. Adapted from Robinson et al. (1987). & $\frac{\left(t_{\mathrm{sw}, \mathrm{R}}-t_{\mathrm{sW}, \mathrm{L}}\right)}{0.5\left(t_{\mathrm{sW}, \mathrm{R}}-t_{\mathrm{sW}, \mathrm{L}}\right)} 100 \%$ & \\
\hline Al step length & $\mathrm{Al}_{\text {step }}$ & Asymmetry index of step length. Adapted from Robinson et al. (1987). & $\frac{\left(I_{\text {step }, \mathrm{R}}-I_{\text {step }, \mathrm{L}}\right)}{0.5\left(I_{\text {step }, \mathrm{R}}-I_{\text {step }, \mathrm{L}}\right)} 100 \%$ & \\
\hline Al duty factor & $\mathrm{Al}_{\mathrm{df}}$ & Asymmetry index of duty factor. Adapted from Robinson et al. (1987). & $\frac{\left(d f_{R}-d f_{L}\right)}{0.5\left(d f_{R}-d f_{L}\right)} 100 \%$ & - \\
\hline
\end{tabular}

Normalized variables are indicated with primes. L, left; $R$, right.

underlying neuromotor and biomechanical (i.e. neuro-mechanical) system (Aerts et al., 2000; Nishikawa et al., 2007; Segers et al., 2006). As such, relative phasing of the limbs reveals interlimb coordination, while single limb behaviour (during stance and swing) is a collective measure of intralimb coordination. The abovementioned general question can thus be reformulated as follows: is the spatio-temporal behaviour constant during early development in piglets, indicating fully innate control in this precocial species? Or does the spatio-temporal behaviour rapidly change over time anyway, as is suggested for neonate altricial species (Dominici et al., 2011; Grillner, 2011; Lacquaniti et al., 2012b)?

In order to assess changes or constancy in the spatio-temporal behaviour during early development, the potential growth and eventual postural changes of the piglets should be taken into account. With the change of inertia, the dynamics of kinematically identical locomotor tasks will change as well. Alexander and Jayes (1983) argue that two motions are dynamically similar if they could be made identical by applying uniform scaling factors for linear dimensions, time and forces (see also Alexander, 1977). Therefore, in order to answer the above general question, the spatio-temporal behaviour at voluntary $u$ was normalized according to the dynamical similarity concept for terrestrial locomotion (e.g. Alexander, 2003; Hof, 1996). This results in the dimensionless spatio-temporal variables presented in Table 1 [note that $u^{\prime}$ is equal to the square root of the Froude number as mostly used in locomotor studies; identical $u^{\prime}$ (or $u^{\prime 2}$ ) values mean dynamically equivalent (dimensionless) locomotor speeds].

More specifically we aimed to answer the following questions. (1) Is voluntary locomotion at $u^{\prime}$ dynamically similar during early gait development? We hypothesize that this is the case, implying that the dynamical task for the motor system does not change during this early developmental period. For this purpose, we compared $u^{\prime}$ between developmental stages and how this $u^{\prime}$ is established [in terms of normalized stride frequency $\left(f^{\prime}\right)$ and normalized stride length $\left.\left(l_{\text {stride }}{ }^{\prime}\right)\right]$. If $u^{\prime}, f^{\prime}$ and $l_{\text {stride }}{ }^{\prime}$ do not change, the hypothesis will be confirmed. (2) Does interlimb coordination change during early gait development? We hypothesize that this is not the case, implying established innate interlimb coordination. For this purpose, we 
compared the relative phasing of the limbs between developmental stages. Relative phasing includes the front lag (f-lag), hind lag (h-lag), pair lags (p-lag) and diagonal lags (d-lag). If these relative timings of the footfalls do not change, the hypothesis will be confirmed. (3) Does the individual limb behaviour (intralimb coordination) change during early gait development? We hypothesize that this is not the case, implying established innate intralimb coordination. For this purpose, we compared the normalized swing $\left(t_{\mathrm{sw}}{ }^{\prime}\right)$ and stance durations $\left(t_{\mathrm{st}}{ }^{\prime}\right)$ and the normalized step lengths $\left(l_{\text {step }}{ }^{\prime}\right)$ between developmental stages, as these three variables determine to a large extent the limb configuration. If per limb these variables do not change, the hypothesis will be confirmed. However, we also hypothesize that, given the body build, a difference between front and hind limbs will be present. To this end, we compared duty factor (df) between leg pairs. (4) Does the variability of the gait pattern change during early gait development? We hypothesize this is the case and gait variability decreases rapidly during early development, leading to a stable gait pattern. We compared left-right asymmetries within the locomotor cycles between developmental stages to assess this variability.

Confirmation of all these hypotheses will support the assumption of complete innate locomotor control in pigs and possibly in other precocial mammals.

\section{MATERIALS AND METHODS Selection of piglets}

Institutional and national guidelines for the care and use of animals were followed and all experimental procedures involving animals were approved by the Ethical Committee of Animal Experimentation, University of Antwerp, Belgium (approval number 2015-26). The data were collected from 14 domestic piglets (Sus scrofa, Topigs $\times$ Belgian Piètrain) between 12 February and 11 May 2015 on a local farm. Seven litters were monitored, with 1-3 healthy piglets selected per litter. Upon selection, the piglets were ear notched. The average number of piglets born alive within these litters was $15.71 \pm 4.39$ (mean \pm s.d., here and throughout). Sex was not used as a selection criterion (although 7 females and 7 males were included). Piglets were chosen based on their body mass at birth and vitality score. Each piglet was weighed at birth and its vitality was scored ( $0-4$, dead to normal vitality), based on respiration ( $0-2$, no to regular respiration) and movement $(0-2$, no movement to taking a few steps). This way of scoring is based on the Apgar score of human neonates, but has been modified for piglets (Zaleski and Hacker, 1993; Randall, 1971). Animals that scored 3 or 4 out of 4 were considered to have a normal vitality. Piglets with a birth mass that was within the limits of the average birth mass in the litter \pm 1 s.d. were classified as normal birth mass piglets. Only piglets that were classified as being of normal birth mass with normal vitality were used. The mean birth mass of the piglets was $1.19 \pm 0.23 \mathrm{~kg}$. The piglets that were included in the study were also weighed at each walking session. All relevant data for included piglets are listed in Tables $\mathrm{S} 1-\mathrm{S} 7$.

\section{Video sequences}

Lateral view video recordings were made of the animals when walking through a corridor, perpendicular to the camera (3.3 megapixel, $50 \mathrm{~Hz}$ deinterlaced, JVC GZ-V515, JVC Kenwood Corporation, Kanagawa, Japan), provided with a reference grid (see Fig. 1). The corridor was $0.2 \mathrm{~m}$ in width, $1.5 \mathrm{~m}$ in length with a polymethyl methacrylate (Plexiglas ${ }^{\circledR}$ ) wall on one side. The surface of the corridor was covered with anti-skid material (rubber) for

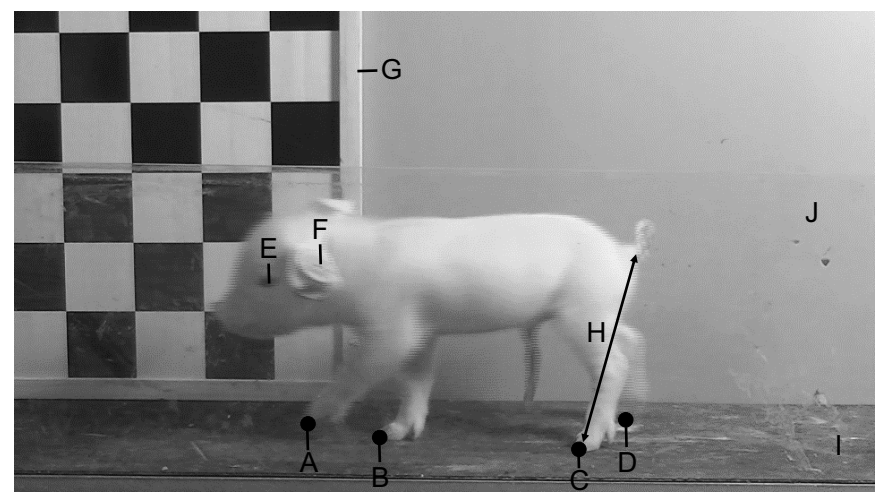

Fig. 1. Lateral view of the recording set-up (video still image). A: digitized point on left front leg; $\mathrm{B}$ : digitized point on right front leg; $\mathrm{C}$ : digitized point on left hind leg; D: digitized point on right hind leg; E: eye; F: ear-notch; G: reference grid; $\mathrm{H}$ : functional hind limb length at midstance; I: corridor with anti-skid material; J: Plexiglas ${ }^{\circledR}$ wall.

optimal grip. Ten time points $(0,1,2,4,6,8,24,26,28$ and $96 \mathrm{~h}$ after birth) were chosen. To study the maturation of locomotion, it was necessary to choose a control age to which all other ages were compared. Initially, in view of our hypotheses regarding the innateness of locomotion, $0 \mathrm{~h}$ was considered as a control age. However, the variation at this age was considerable, in comparison to the other ages. Additionally, this way of working would have provided us with no information regarding the exact timing of maturation. Keeping this in mind, we opted to use age 96 h, a time point with minimal variation that was still within the frame of early development (see above). Furthermore, age $96 \mathrm{~h}$, later referred to as control age $96 \mathrm{~h}$ (CA $96 \mathrm{~h}$ ), is an exceptionally relevant age in early piglet development, because mortality is highest during the first 3 postnatal days (Quiniou et al., 2002; Tuchscherer et al., 2000).

Piglets were gently encouraged to walk at voluntary $u$ through the corridor. To avoid fatigue, only three successive trials were recorded at each time point per piglet. From these trials, we aimed at retaining two sequences in which the piglets completed at least one entire cycle (stride) without pausing or falling for further analysis. One animal died just prior to CA $96 \mathrm{~h}$ and 12 trials (from 9 piglets at four developmental points) were discarded because of the lack of a complete stride. As such, 266 (out of 280) trials were included in the analysis.

\section{Gait analysis}

In all video sequences, five body points were digitized field-by-field using Matlab (Mathworks, Natick, MA, USA), using a free work package written by Ty Hedrick (University of North Carolina, USA; http://www.unc.edu/ thedrick/software1.html): the most distal point of the distal phalanx of each leg and either the eye or the ear notch. As no information on the exact position of the centre of mass (COM) was available, the displacements of the eye or the ear notch were used as a proxy for overall forward displacement of the body throughout the stride. The choice of either eye or ear notch was determined for each sequence separately and preliminary tests showed the forward displacement was correctly represented by both. Our preference was the ear notch, the landmark that was most easily traceable throughout an entire sequence. The ear in these young piglets is a rigid structure that moves with the head. As there were no conspicuous head movements throughout a stride, it is assumed to represent the forward movement of the body accurately. However, for some sequences, it was not possible to use the ear notch. To encourage voluntary locomotion, the piglets were able to choose the 
direction of movement (left to right or right to left). As such, the ear notch was sometimes located on the side of the animal that was invisible to the camera. When this was the case, we opted to use the eye as a proxy for COM. However, it was not feasible to use the eye for all movies throughout the analysis, for practical reasons. All movies were made at close range to provide enough detail for subsequent analysis. As such, the eye was sometimes no longer visible in the frame, while the stride was still ongoing. In these cases, the ear notch was still visible, because of its more caudal location. In addition, some animals only opened their eyes after a few hours, making it a hard landmark to trace.

Additionally, a locomotion-related linear dimension needed to be digitized for normalization purposes (see below). Traditionally, hip height is used for normalization, according to the dynamic similarity principle (Alexander, 1992b). However, for these young piglets it was impractical to measure hip height. Newborn pigs typically have very loose skin, which not only makes the hip joint very difficult to localize and mark correctly but also results in large marker displacements during locomotion as a result of skin movement. As such, we opted to use the functional leg length/ height $(H)$, i.e. the distance between the most distal part of the distal phalanx and a fixed point on the pelvis, i.e. the tail base. These landmarks can be digitized unequivocally, which minimizes the measurement error (and hence the non-biological variation in our data). $H$ was determined for each sequence, in the frame coinciding with midstance of the hind limb closest to the camera. Two points of the reference grid were digitized for scaling purposes.

From the digitizations of these five body points, 19 gait-related variables were calculated using a custom-written Matlab script (J.G.). An overview of these variables, including definitions and formulas, can be found in Table 1. Variables were calculated per piglet ( $u, u^{\prime}$ and time lags), per leg pair (asymmetry indices, AIs) or per leg (spatio-temporal gait variables). AIs were used as a proxy for variability. According to Meijer et al. (2014), absolute AI values can range from $200 \%$ to $0 \%$, the latter being indicative of perfect contralateral symmetry. In accordance with the dynamical similarity (Alexander and Jayes, 1983), $u$ and all spatio-temporal gait variables were normalized to $H$. All formulas used for normalization of the parameters can also be found in Table 1.

\section{Statistics}

Linear mixed models were fitted to evaluate the effect of age and leg on the outcome variables. Fixed factors included age and leg (if relevant for the parameter in question), and sex was included as a covariate. To account for the dependence between observations on littermates or within the same animal, random factors were included for sow and piglet (nested in sow), plus random slopes for age, leg and piglet (nested in sow). The starting model was simplified using stepwise backwards modelling. Some outcome variables required no transformations ( $u^{\prime}, \mathrm{df}, l_{\text {stride }}{ }^{\prime}, l_{\text {step }}{ }^{\prime}$ and p-lag); others were either log-transformed $\left[t_{\text {st }}{ }^{\prime}, f^{\prime}\right.$, AI stride length $\left(\mathrm{AI}_{l_{\text {stride }}}\right)$, AI step length $\left(\mathrm{AI}_{l_{\text {step }}}\right)$, AI duty factor $\left(\mathrm{AI}_{\mathrm{df}}\right)$, f-lag, h-lag, d-lag] or square-root transformed $\left[t_{\mathrm{sw}}{ }^{\prime}, \mathrm{AI}\right.$ stride frequency $\left(\mathrm{AI}_{f}\right)$, AI stance duration $\left(\mathrm{AI}_{t_{\mathrm{s}}}\right)$, AI swing duration $\left(\mathrm{AI}_{t_{\mathrm{sw}}}\right)$ ] to meet normality and/or homoscedasticity assumptions. Models were fitted using JMP ${ }^{\circledR}$ Pro 12 (SAS Institute Inc., Cary, NC, USA). An effect was considered to be statistically significant if $P \leq 0.05$. Post hoc analysis with Dunnett's correction was used for comparing the different age groups to CA $96 \mathrm{~h}$ for $u^{\prime}, f^{\prime}, l_{\text {stride }}{ }^{\prime}, t_{\mathrm{sw}}{ }^{\prime}, t_{\mathrm{st}}{ }^{\prime}, l_{\text {step }}{ }^{\prime}$ and AIs. Post hoc analysis with Tukey's correction was used to compare the different legs for df and $t_{\mathrm{sw}}{ }^{\prime}$.

\section{RESULTS}

\section{Morphometrics}

The change in body mass and $H$ (used for normalization) with age is shown in Fig. 2. During the first 28 h, body mass gain was limited
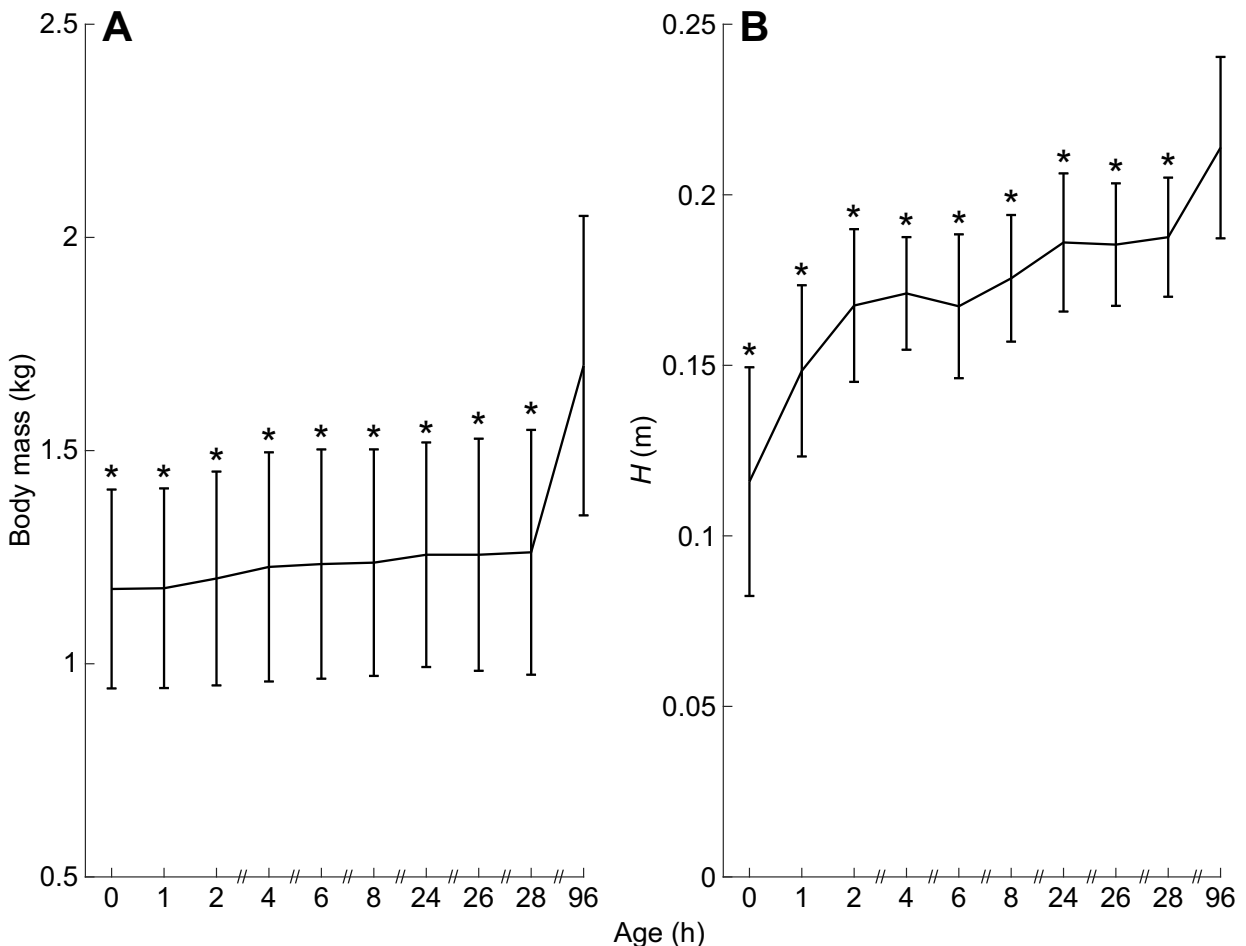

Fig. 2. Morphometrics. (A) Body mass $(n=137)$. (B) Functional hind limb length $(H, n=137)$. Linear mixed models, post hoc analysis with Dunnett's correction. All values are means \pm s.d. *Mean values differ significantly from the control age (CA) of $96 \mathrm{~h}$ $(P \leq 0.05)$ 
( $0.46 \%$ of the body mass at birth). The rapid initial increase in $H$ (between 0 and $2 \mathrm{~h}$ ) can mainly be attributed to a more erect limb posture, rather than to growth.

\section{How do absolute gait data change during early development?}

Up to and including age $8 \mathrm{~h}, u$ was significantly lower than at CA $96 \mathrm{~h}(P<0.0001$ for ages 0 and $1 \mathrm{~h}, P=0.0150,0.0049,0.0126$ and 0.0181 for ages 2, 4, 6 and $8 \mathrm{~h}$, respectively; Fig. 3A). At age $0 \mathrm{~h}, u$ of the piglets was only $0.09 \mathrm{~m} \mathrm{~s}^{-1}$, while at CA $96 \mathrm{~h}$ they were walking at a pace of $0.23 \mathrm{~m} \mathrm{~s}^{-1}$. $l_{\text {stride }}$ and $l_{\text {step }}$ showed similar results (Fig. 3B,C). Both $l_{\text {stride }}$ and $l_{\text {step }}$ reached a stable value between age 24 and $26 \mathrm{~h}\left(l_{\text {stride }}\right.$ : all $P<0.0001$, except $P=0.0199$ for age $24 \mathrm{~h} ; l_{\text {step }}$ : all $P<0.0001$, except $P=0.0210$ for age $24 \mathrm{~h}$ ). $l_{\text {stride }}$ increased from $0.08 \mathrm{~m}$ at age $0 \mathrm{~h}$ to $0.19 \mathrm{~m}$ at $\mathrm{CA}$ $96 \mathrm{~h}$. For $l_{\text {step }}$, we found a similar increase from $0.06 \mathrm{~m}$ (age $\left.0 \mathrm{~h}\right)$ to $0.14 \mathrm{~m}$ (CA $96 \mathrm{~h}) . f$ did not significantly change with age (Fig. 3D).

\section{Is voluntary locomotion at normalized self-selected speed dynamically similar during early gait development?}

$u^{\prime}$ did not change any further $2 \mathrm{~h}$ after birth (Fig. 4A). This is evidenced by the fact that $u^{\prime}$, compared with CA $96 \mathrm{~h}$, was only significantly different for ages 0 and $1 \mathrm{~h}(P<0.0001$ and 0.0055 , respectively). $u^{\prime}$ at these ages was significantly lower, comprising only $50.34 \%$ (age $0 \mathrm{~h}$ ) and $63.46 \%$ (age $1 \mathrm{~h}$ ) of the $u^{\prime}$ at CA $96 \mathrm{~h}$. We saw similar results for $f^{\prime}$ and $l_{\text {stride }}$ (Fig. 4B,C). $f^{\prime}$ reached a stable value between ages 0 and $1 \mathrm{~h}$, which is indicated by the fact that the piglets only showed a significantly lower $f^{\prime}$ at age $0 \mathrm{~h}(85.27 \%$ of $\mathrm{CA} 96 \mathrm{~h} ; P=0.0012) . l_{\text {stride }}{ }^{\prime}$ took longer to reach a steady value. When compared with $\mathrm{CA} 96 \mathrm{~h}, l_{\text {stride }}$ was significantly lower at ages $0 \mathrm{~h} \quad(P=0.0006)$ and $2 \mathrm{~h}$ $(P=0.0125)$, being $72.86 \%$ and $79.12 \%$ of the CA $96 \mathrm{~h}$ value, respectively.

\section{Does interlimb coordination change during early gait development?}

We found that the different time lags did not change significantly with age. Values for f-lag, h-lag, p-lag (left), p-lag (right), d-lag (left hind, right front) and d-lag (right hind, left front) were $0.53 \pm 0.16$, $0.50 \pm 0.13, \quad 0.69 \pm 0.17, \quad 0.36 \pm 0.18, \quad 0.25 \pm 0.19$ and $0.20 \pm 0.11$, respectively.

\section{Does intralimb coordination change during early gait development?}

$t_{\mathrm{sw}}{ }^{\prime}$ was $24.65 \%$ lower at age $2 \mathrm{~h}$ compared with the value at $\mathrm{CA}$ $96 \mathrm{~h}\left(P=0.0002\right.$; Fig. 5A). Initially, at age $0 \mathrm{~h}, t_{\mathrm{sw}}{ }^{\prime}$ was similar to that at CA $96 \mathrm{~h} . t_{\mathrm{st}}{ }^{\prime}$ showed a significantly higher value at age $0 \mathrm{~h}$ compared with the CA $96 \mathrm{~h}$ value $(183.28 \%$ of CA $96 \mathrm{~h} ; P=0.0018$; Fig. 5B). However, between age 0 and $1 \mathrm{~h}, t_{\mathrm{st}}{ }^{\prime}$ reached a steady value. $l_{\text {step }}$ ' reached a stable value between ages 2 and $4 \mathrm{~h}$ as shorter $l_{\text {step }}$ ' were observed at ages $0 \mathrm{~h}(78.69 \%$ of CA $96 \mathrm{~h} ; P=0.006)$ and $2 \mathrm{~h}(83.46 \%$ of CA 96 h; $P=0.0495$; Fig. 5C).

\section{Does intralimb coordination differ as a function of body} build?

The front legs exhibited a higher df than the hind legs [left front (LF)-left hind (LH); LF-right hind $(\mathrm{RH})$; right front (RF)-RH
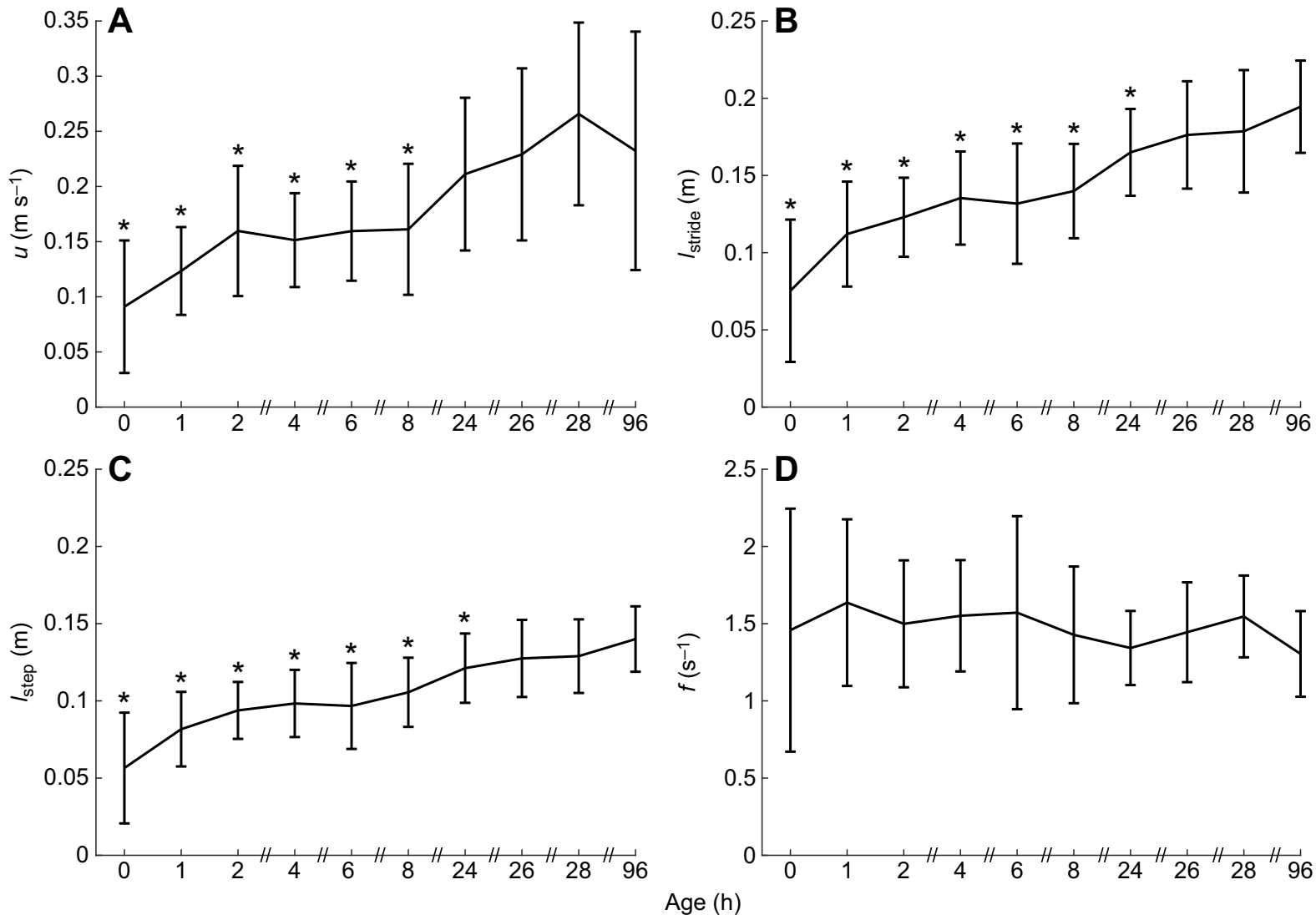

Fig. 3. Absolute gait data. (A) Self-selected speed $(u, n=137)$. (B) Stride length ( $\left(I_{\text {stride }}, n=548\right)$. (C) Step length $\left(I_{\text {step }}, n=548\right)$. (D) Stride frequency $(f, n=548)$. Linear mixed models, post hoc analysis with Dunnett's correction. All values are means \pm s.d. * Mean values differ significantly from CA $96 \mathrm{~h}(P \leq 0.05)$. 

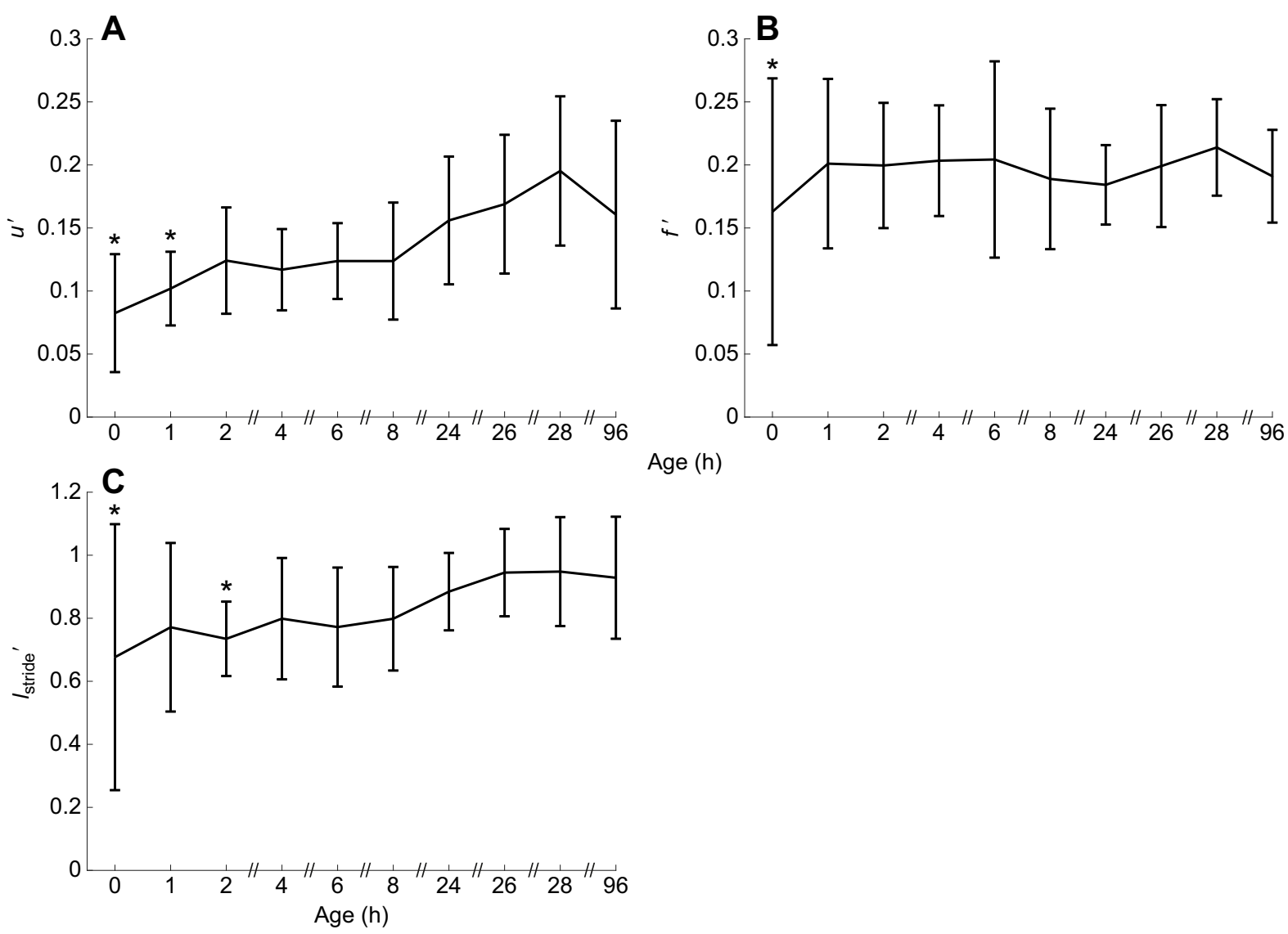

Age (h)

Fig. 4. Dimensionless gait data. (A) Normalized self-selected speed $\left(u^{\prime}, n=137\right)$. (B) Normalized stride frequency $\left(f^{\prime}, n=548\right)$. (C) Normalized stride length $\left(I_{\text {stride }}, n=548\right)$. Linear mixed models, post hoc analysis with Dunnett's correction. All values are means $\pm s . d .{ }^{*}$ Mean values differ significantly from CA $96 \mathrm{~h}$ $(P \leq 0.05)$.

differ significantly with a $P<0.0001$; RF-LH differ with a $P=0.0004]$, with differences within both leg pairs being negligible (LF $0.76 \pm 0.07$, RF $0.75 \pm 0.08$; versus LH $0.72 \pm 0.08$, $\mathrm{RH}$

$0.71 \pm$

0.09 ; Fig. 6A). The hind legs showed an overall $t_{\mathrm{sw}}{ }^{\prime}$ that was $15.33 \%$ longer than that of the front legs (LF and RF versus RH: $P<0.0001$, LF versus LH: $P=0.0002$; RF vs LH: $P=0.0003$; Fig. 6B).

\section{Does gait (a)symmetry change during early gait development?}

Values for $\mathrm{AI}_{f}$ and $\mathrm{AI}_{l_{\text {stride }}}$ at $0,1,2$ and $6 \mathrm{~h}$ differed significantly from those at CA $96 \mathrm{~h}(P<0.0001,0.0037,0.0388$ and 0.0333 , respectively, for $\mathrm{AI}_{f}$; and $P<0.0001,0.0004,0.0315$ and 0.0231 , respectively, for $\mathrm{AI}_{l_{\text {stride }}}$; Fig. 7A,B). Both $\mathrm{AI}_{f}$ and $\mathrm{AI}_{l_{\text {stride }}}$ were higher at early ages (for ages $0,1,2$ and $6 \mathrm{~h}, \mathrm{AI}_{f}$ was $54.69 \pm 35.32 \%, 30.13 \pm 26.63 \%, 23.99 \pm 18.58 \%$ and $27.20 \pm$ $31.14 \%$, respectively, and $\mathrm{AI}_{l_{\text {stride }}}$ was $107.08 \pm 232.13 \%, 30.28 \pm$ $20.47 \%, 21.33 \pm 12.49 \%$ and $28.67 \pm 25.80 \%$, respectively). At CA $96 \mathrm{~h}, \mathrm{AI}_{f}$ and $\mathrm{AI}_{l_{\text {stride }}}$ were reduced to $9.75 \pm 6.72 \%$ and $12.4 \pm$ $8.12 \%$. We also observed a reduction in $\mathrm{AI}_{t_{\mathrm{sw}}}$ (Fig. $7 \mathrm{C}$ ). While at age $0 \mathrm{~h}$ we noted an $\mathrm{AI}_{t_{\mathrm{sw}}}$ of $53.86 \pm 41.49 \%$, this was reduced to $25.94 \pm 13.71 \%$ at $\mathrm{CA} 96 \mathrm{~h}(P=0.0065) . \mathrm{AI}_{t_{\mathrm{st}}}$ reached a stable value between the ages of 6 and $8 \mathrm{~h}$ (Fig. 7D). $\mathrm{AI}_{t_{\mathrm{st}}}$ at ages $0,1,2$ and $6 \mathrm{~h}$ was significantly higher $(70.59 \pm 32.82 \%, 36.67 \pm 30.79 \%, 28.54 \pm$ $21.76 \%$ and $35.53 \pm 37.04 \%)$ than $\mathrm{AI}_{t_{\mathrm{st}}}$ at $\mathrm{CA} 96 \mathrm{~h}(12.49 \pm 9.12 \%$; $P<0.0001,=0.0019,=0.0291$ and $=0.0071$, respectively). $\mathrm{AI}_{l_{\text {step }}}$ at ages $0,1,2$ and $6 \mathrm{~h}$ was $120.34 \pm 227.76 \%, 37.11 \pm 23.65 \%, 23.27 \pm$ $14.18 \%$ and $34.50 \pm 34.30 \%$ (Fig. $7 \mathrm{E}$ ), and thus significantly higher when compared with the value at CA $96 \mathrm{~h}(P<0.0001$, $<0.0001,=0.0091$ and $=0.0012$, respectively). At CA $96 \mathrm{~h}$, we observed an $\mathrm{AI}_{l_{\text {step }}}$ of $11.06 \pm 7.95 \%$. Comparing leg pairs, we saw that the front leg pair showed a lower $\mathrm{AI}_{\mathrm{df}}(10.56 \pm 9.70 \%)$ than the hind leg pair $(13.08 \pm 9.41 \% ; P=0.0010$; Fig. $7 F)$. For $\mathrm{AI}_{t_{\mathrm{sw}}}$, we did not observe a difference between the front and the hind leg pair.

\section{DISCUSSION}

\section{Morphometrics}

The present results show that early neonatal development in piglets is characterized by growth in terms of body mass, contributing to a longer $H$. Along with growth, we also saw postural changes during the first few hours. This more upright position of the piglets and extension of the legs resulted in a better positioning of the limbs for walking and a longer $H$. Both growth and the postural changes go along with an increase in $u, l_{\text {stride }}$ and $l_{\text {step. These changes in body }}$ mass and limb length during early development were also observed in other studies (on different species, including pigs; e.g. Sutherland, 1997; Clarke and Still, 2001; Stavrakakis et al., 2014; Back et al., 1994). However, the observed shifts in the absolute spatio-temporal gait may equally well represent additional effects to those of growth and postural changes such as neuromotor maturation. We argue (see Introduction) that, if only growth and posture contribute in this early phase, spatio-temporal gait 

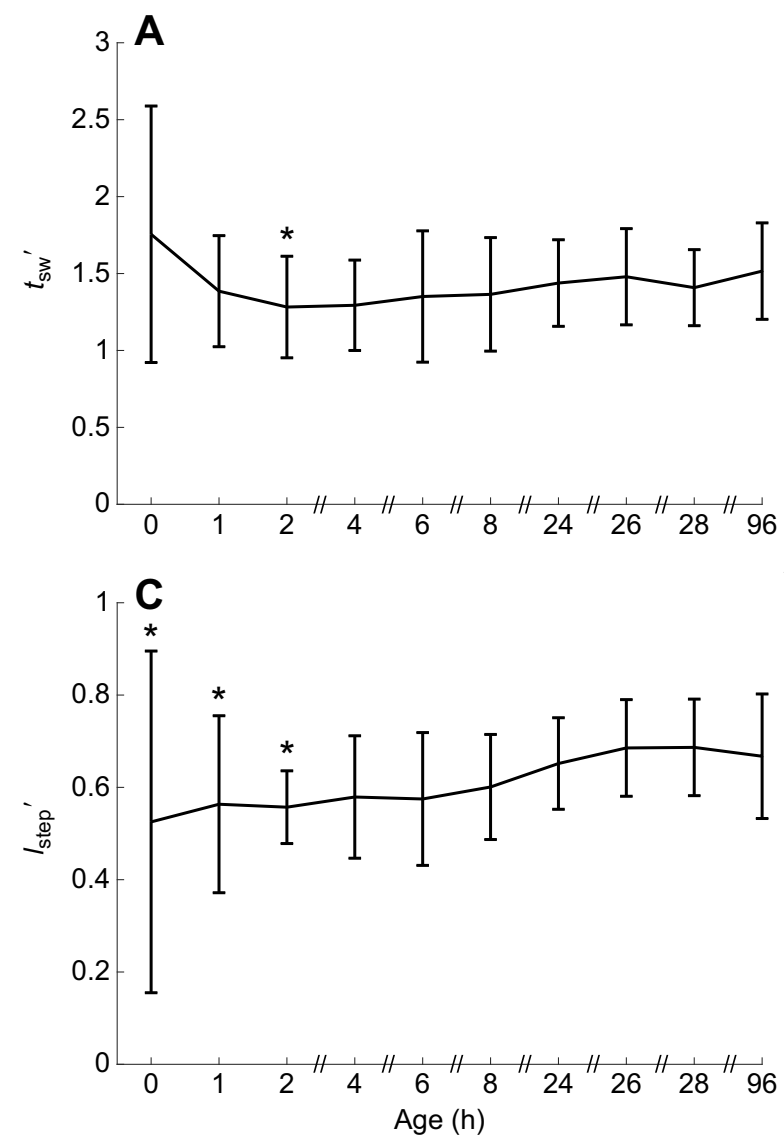

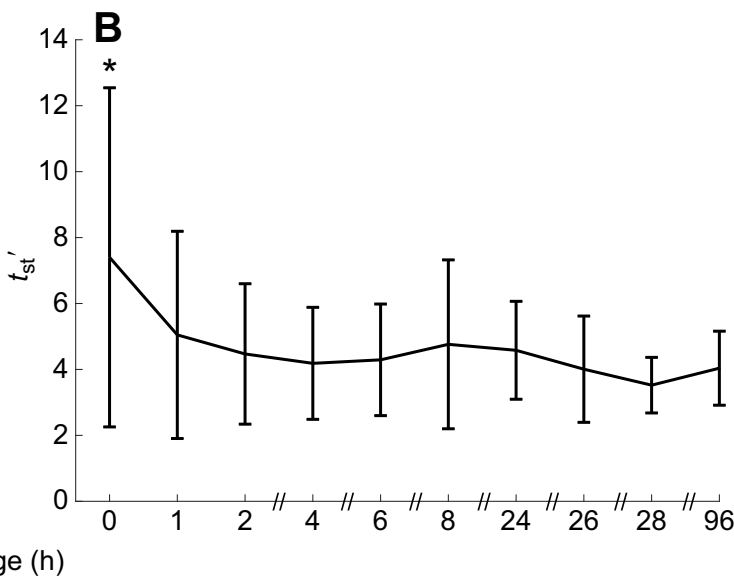

Age (h)

Fig. 5. Intralimb coordination - age differences. (A) Normalized swing duration ( $\left.t_{\mathrm{sw}}{ }^{\prime}, n=548\right)$. (B) Normalized stance duration $\left(t_{\mathrm{st}}{ }^{\prime}, n=548\right)$. (C) Normalized step length $\left(I_{\text {step }}, n=548\right)$. Linear mixed models, post hoc analysis with Dunnett's correction. All values are means $\pm s . d .{ }^{*}$ Mean values differ significantly from CA $96 \mathrm{~h}(P \leq 0.05)$

characteristics, normalized according to the dynamic similarity principle (see, for instance, Alexander, 2003, for details), would remain constant over the considered developmental period. If the dynamics of the motor task (implicitly taking size into account) do not change during development, then the neuromotor patterns are also assumed to remain constant. This implies no further maturation at this level. Otherwise, changes of the normalized data (according to dynamic similarity) would indicate neuromotor maturation on top of pure 'size' effects. In case of altricial species, both absolute and normalized gait characteristics will presumably change during early development. In precocial species, in contrast, normalized gait characteristics are assumed to be constant or to stabilize very rapidly after birth. Below, we discuss the locomotor developmental data of the piglets from this point of view.

\section{Is voluntary locomotion at self-selected speed dynamically similar during early gait development?}

Apart from the $2 \mathrm{~h}$ after birth, $u^{\prime}$ seemed to be invariable during the first 4 days, suggesting a very rapid stabilization of the motor task. During the first hour after birth, $u^{\prime}$ was lower compared with the CA value. Between the ages of 1 and $2 \mathrm{~h}$, a steady value for $u^{\prime}$ was reached, which was due to an adjustment of both $l_{\text {stride }}{ }^{\prime}$ and $f^{\prime}$ (the product equalling $\left.u^{\prime}\right)$. The first component of $u$, i.e. $l_{\text {stride, }}$ increased up to and including the age of $24 \mathrm{~h}$, as a result of the growth of the piglets. This has been reported for wildebeest, where a comparison of juveniles and adults showed an increase of $l_{\text {stride }}$ with age (Pennycuick, 1975). However, as $l_{\text {stride }}$ 'reached a stable value between the ages of 2 and $4 \mathrm{~h}$, we deduce that during these first $4 \mathrm{~h}$, neuromotor maturation takes place.

$f$, the other component of $u$, remained constant during early development, while $f^{\prime}$ rapidly increased after birth, reaching a consistent value between ages 0 and $1 \mathrm{~h}$. This difference between $f$ and $f^{\prime}$ is explained by the rapid increase in $H$ in this early developmental period. One of the few longitudinal studies available on precocial species is on the horse, detailing $f$ (not $f^{\prime}$ ) (Back et al., 1994). Contrary to our (non-normalized) results, Back et al. (1994) reported a decrease in $f$ with age (until 26 months), as a result of increased height at the withers. The result for wildebeest also shows a decrease in $f$ from juvenile into adulthood (Pennycuick, 1975). This might imply a great difference in gait maturation among precocial animals, as we saw no change in $f$ with age for pigs. Clearly, the developmental period considered in these previous studies differs considerably from ours. Studying pigs up to and including the age of 84 days, Liu et al. (1999) concluded that the absolute growth rate of the legs increases with age. This implies that, for older piglets (beyond the age of $96 \mathrm{~h}$ ), absolute gait variables, such as $l_{\text {stride }}$ and $f$, might change in a fashion similar to the horse and the wildebeest. Furthermore, the apparent contrast with our results stresses the importance for the need for normalized data in order to tell whether the decrease in $f$ in horses and/or wildebeest is exclusively an effect of growth, or whether this represents a neuromotor maturation pattern.

The increase of both $l_{\text {stride }}{ }^{\prime}$ and $f^{\prime}$ (with a higher $u^{\prime}$ as a consequence) we saw in piglets has also been reported for humans 


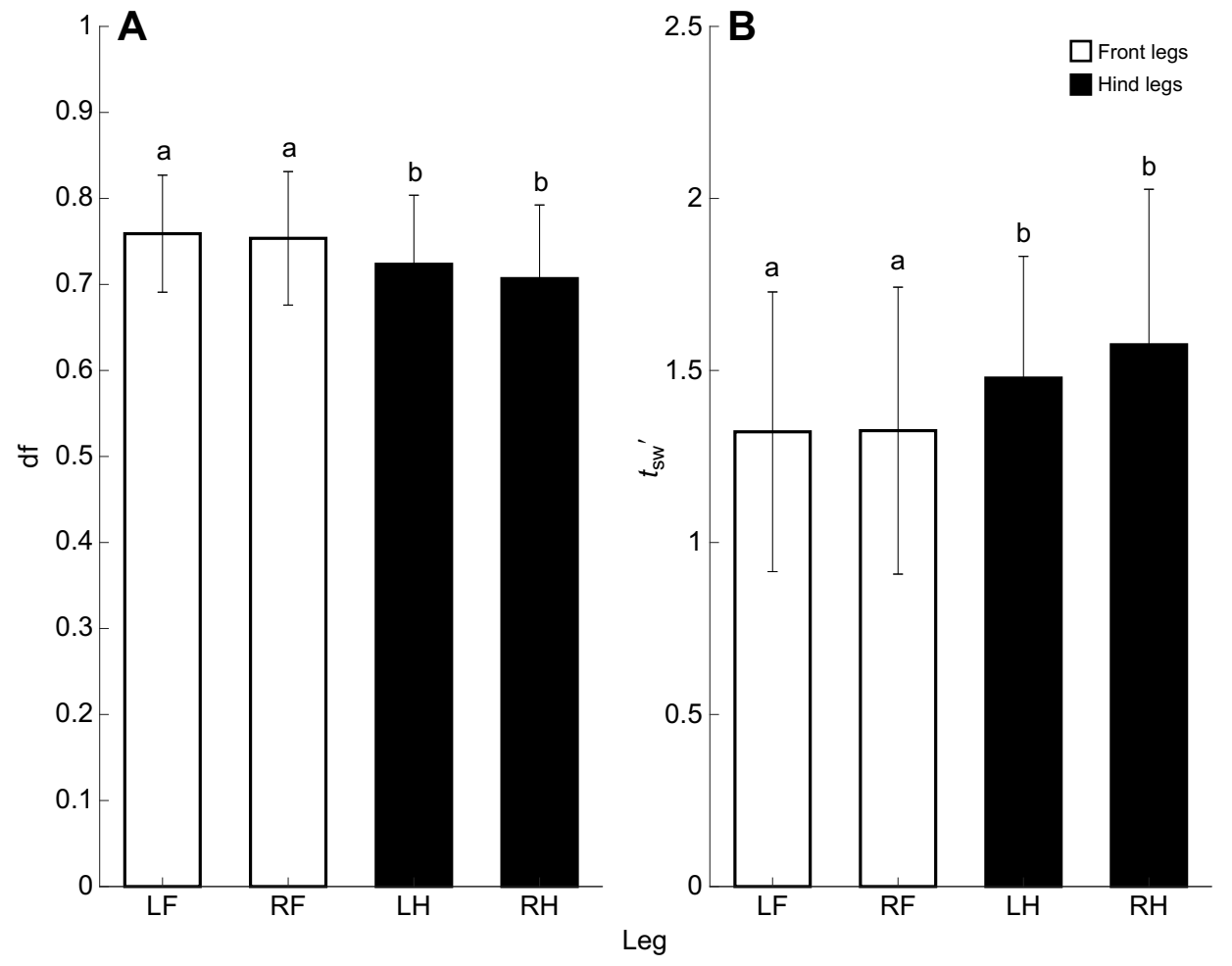

Fig. 6. Intralimb coordination - leg differences. (A) Duty factor (df, $n=548$ ).

(B) Normalized swing duration $\left(t_{\mathrm{sw}}{ }^{\prime}, n=548\right)$. Linear mixed models, post hoc analysis with Tukey's correction. All values are means \pm s.d. Significant differences $(P \leq 0.05)$ are indicated by different letters. by Sutherland (1997). By looking at these normalized parameters, it was concluded that both growth and a maturation process influence spatio-temporal gait parameters for children aged $1-4$ years. This is similar to our results, although the time frame is considerably longer in humans, which illustrates the difference between altricial and precocial species.

Overall, once $u^{\prime}$ stabilizes, its components also stabilize, which supports our hypothesis of a very quick neuromotor maturation. The very slight discrepancies in maturation intervals for $u^{\prime}, f^{\prime}$ and $l_{\text {stride }}{ }^{\prime}$ are likely to be due to the large amount of variation in the data.

\section{Does interlimb coordination change during early gait development?}

The footfall pattern of the gait of piglets did not change during early development, which implies that interlimb coordination (relative phasing of the limbs) is completely innate in pigs. Our results indicate that piglet gait can be classified as the 'lateral walk' type, with f-lags and h-lags of around 50\% and one p-lag (in this case, left) of more than $50 \%$ of the total cycle duration (Abourachid, 2003; Abourachid et al., 2007). This is in accordance with findings for adult pigs (von Wachenfelt et al., 2008).

\section{Does intralimb coordination change during early gait development?}

Unlike interlimb coordination, intralimb coordination does not seem to be fully innate, which is indicated by $t_{\mathrm{sw}}{ }^{\prime}$ and $t_{\mathrm{st}}{ }^{\prime}$, as well as $l_{\text {stride }}{ }^{\prime}$, showing a fast maturation process. From our results, it seems the duration of $t_{\mathrm{sw}}{ }^{\prime}$ is rather unstable and short during the first $2 \mathrm{~h}$ after birth. Piglets are born with very limited energy reserves (consisting mainly of glycogen). After 20-30 min, they have to start taking in new energy by means of colostrum, to sustain not only their physical activity but also thermoregulation (Theil et al., 2011, 2014; Noblet et al., 1997; Le Dividich et al., 2005). Because of this limited amount of available energy, we propose that during the first hours after birth, the piglet would adopt a means of locomotion that is as energy efficient as possible. One way of accomplishing this is by limiting $t_{\mathrm{sw}}{ }^{\prime}$. During the swing phase, the front or rear end of the animal is only supported by one leg. However, maintenance of stance requires not only the support of the body against gravity but also that the COM remains within the limits of support in the horizontal plane (Fung and Macpherson, 1995). By means of a shorter $t_{\mathrm{sw}}{ }^{\prime}$, the piglet can return more quickly to a phase where the front or rear end of the body is supported by two legs. In addition, it has been argued that the leg swing may consume a substantial part of the stride energy (e.g. Marsh et al., 2004; Arellano and Kram, 2014). Shortly after the age of 2 h, we noted a slight increase in $t_{\mathrm{sw}}{ }^{\prime}$ that led to a stable value between the age of 2 and $4 \mathrm{~h}$. Generally, little is known about the link between $t_{\mathrm{sw}}$ and age, let alone $t_{\mathrm{sw}}{ }^{\prime}$ and age. The longitudinal pattern of $t_{\mathrm{sw}}$ has been studied in one precocial species so far: the horse (Back et al., 1994). Back et al. (1994) revealed that $t_{\mathrm{sw}}$ divided by height decreased up to 26 months in the horse. This decrease (although on a smaller time scale) of $t_{\mathrm{sw}}$ is also visible in altricial species, i.e. mouse and rat (Clarke and Still, 2001; Bolles and Woods, 1964). However, as mentioned earlier, the former studies lack normalized data, which makes it impossible to distinguish maturation from growth and hence make a correct comparison to our piglets.

$t_{\mathrm{st}}{ }^{\prime}$ was initially longer, but reached a lower, stable value during the first hour after birth. We believe there are three possible explanations for this decrease in $t_{\mathrm{st}}{ }^{\prime}$. Firstly, the initially prolonged $t_{\text {st }}{ }^{\prime}$ might be important to increase support immediately after birth. Secondly, we might consider the link between $t_{\mathrm{st}}{ }^{\prime}$ and $u^{\prime}$. It is a wellknown phenomenon that decreasing $t_{\mathrm{st}}$ or $t_{\mathrm{st}}{ }^{\prime}$ leads to an increase in $u$ or $u^{\prime}$ (Pearson, 1976; Verdugo et al., 2013). Thirdly, the decrease in $t_{\mathrm{st}}{ }^{\prime}$ we saw for piglets might in large part be a consequence of the normalization procedure (see Table 1). This way, the initial increase in $H$ due to a more erect positioning of the limbs might greatly influence the values of $t_{\mathrm{st}}{ }^{\prime}$, possibly without influencing $t_{\mathrm{st}}$.

$l_{\text {step }}{ }^{\prime}$ only reached a steady value between 2 and $4 \mathrm{~h}$, which still indicates a very fast maturation process, albeit a little slower than that of $t_{\mathrm{sw}}{ }^{\prime}$ and $t_{\mathrm{st}}{ }^{\prime}$. We argued in the Introduction that single limb 

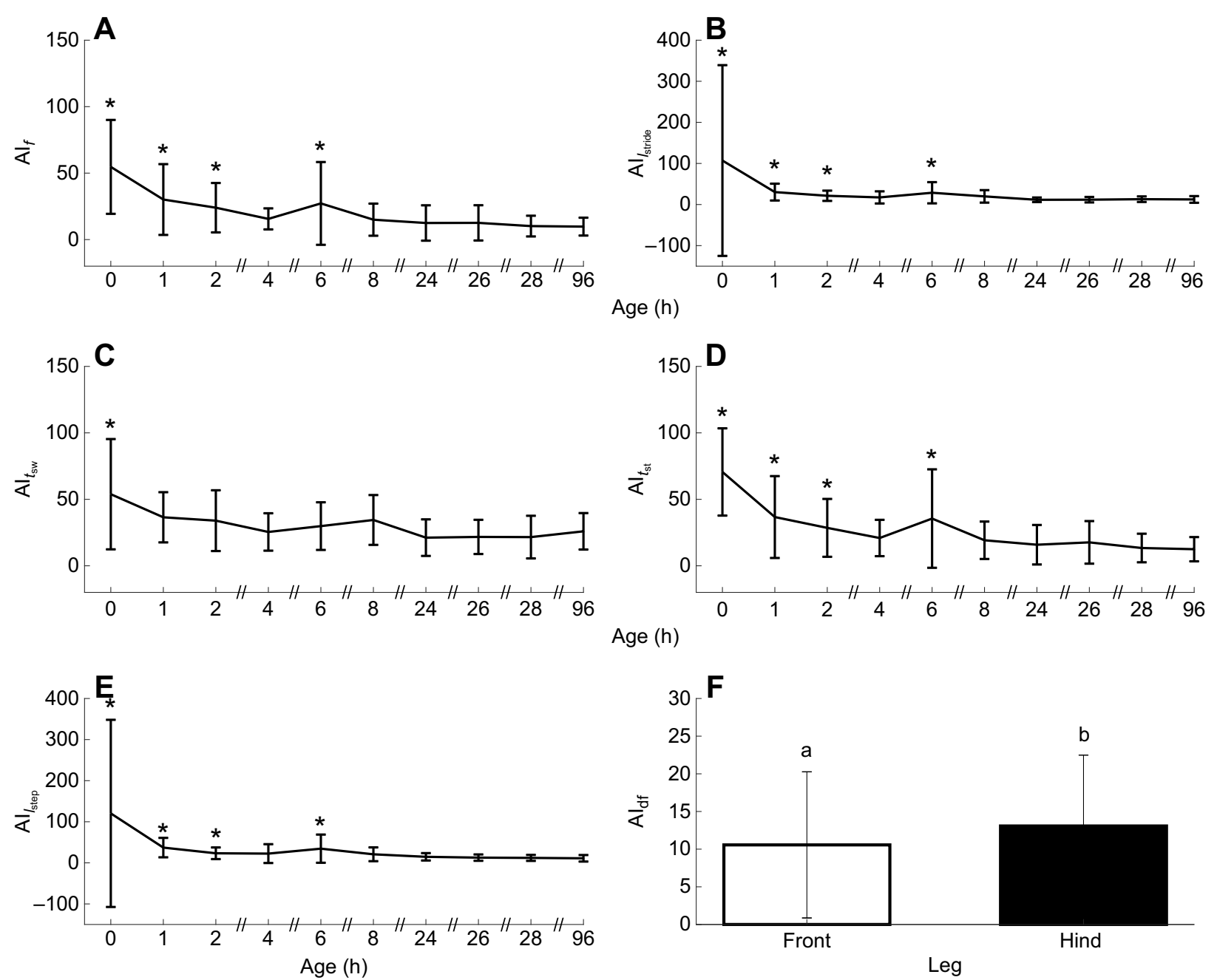

Fig. 7. Asymmetry indices. (A) Asymmetry index of stride frequency $\left(\mathrm{Al}_{f}, n=274\right)$. (B) Asymmetry index of stride length $\left(\mathrm{Al}_{\text {stride }}, n=274\right)$. (C) Asymmetry index of swing duration $\left(\mathrm{Al}_{t_{\text {sw }}}, n=274\right)$. (D) Asymmetry index of stance duration $\left(\mathrm{Al}_{t_{\mathrm{st}}}, n=274\right)$. (E) Asymmetry index of step length $\left(\mathrm{Al}_{l_{\text {step }}}, n=274\right)$. ( $\left.\mathrm{F}\right)$ Asymmetry index of duty factor ( $\mathrm{Al}$ df,$n=274)$. Linear mixed models, post hoc analysis with Dunnett's correction for A-E. Linear mixed model, post hoc analysis with Tukey's correction for $\mathrm{F}$. All values are means \pm s.d. *Mean values in A-E differ significantly from CA $96 \mathrm{~h}(P \leq 0.05)$. Significant differences $(P \leq 0.05)$ in $\mathrm{F}$ are indicated by different letters.

spatio-temporal behaviour can be considered as a collective measure for intralimb coordination. In humans, $l_{\text {step }}$ keeps on increasing until the age of 4 years (Sutherland, 1997) and intralimb coordination rapidly evolves towards mature behaviour, reflecting the inverted pendulum within a few months of independent walking experience (Ivanenko et al., 2004a). This shows once more the difference between precocial and altricial animals.

\section{Does intralimb coordination differ as a function of body build?}

Body mass distribution in pigs (Meijer et al., 2014) and other animals is approximately $30 \%$ on each front limb and $20 \%$ on each hind limb (Besancon et al., 2004; Budsberg et al., 1987; Kim and Breur, 2008; Kano et al., 2016). In line with this, Thorup et al. (2007) showed 54\% of body mass is carried by the pig's forelimbs, which demonstrates that the centre of gravity is relatively close to the forelimbs. In accordance with this unequal distribution of body mass, front limbs and hind limbs generally differ biomechanically, with front limbs receiving higher peak vertical forces than hind limbs. This has been observed for pigs (Thorup et al., 2007), sheep (Kim and Breur, 2008), dogs (Besancon et al., 2004), cats (Verdugo et al., 2013) and mice (Clarke and Still, 1999). As hypothesized, this difference in body mass distribution leads to a difference in df between the front legs and hind legs. The front legs spend a longer time on the ground (see Thorup et al., 2007), as a result of a shorter $t_{\mathrm{sw}}{ }^{\prime}$.

\section{Does the (a)symmetry change during early gait development?}

Symmetry is generally assumed to be a characteristic feature of normal and stable locomotion (Oosterlinck et al., 2010; Herzog et al., 1989; Jeleń et al., 2008; Budsberg et al., 1987; Besancon et al., 2004; Duberstein et al., 2014). Results obtained by Meijer et al. (2014) indicate a very high degree of symmetry in healthy adult pigs. This is in accordance with our findings. We note higher AIs at an early age (ages 0-6 h), and AIs that decrease with time, reaching a value of around $10 \%$ at the control age (similar to AIs in adult pigs; Meijer et al., 2014). This confirms our hypothesis that the variability of the gait pattern (described by means of the AIs) decreases with age, leading to a stable gait pattern a few hours after birth. Keeping in mind that the maximal value of the AI can be $200 \%$, piglets show a high degree of symmetry. The remaining amount of asymmetry $( \pm 10 \%)$ may exist because a gait can never be 
absolutely symmetric, as the body itself does not show perfect leftright symmetry (either anatomical or physiological). Furthermore, to maintain speed, direction and balance, adjustments need to be continuously made by the locomotory system. Even successive walking cycles will not be completely identical and a single trial will have two types of asymmetry: the inherent left-right asymmetry and asymmetry caused by the control system making adjustments (Crowe et al., 1996).

A difference between the front and hind legs was visible in the $\mathrm{AI}_{\mathrm{df}}$. The front legs showed a lower $\mathrm{AI}_{\mathrm{df}}$ than hind legs, indicating that the time the front legs spend on the ground shows less overall variability than the time hind legs spend on the ground. As mentioned above, pigs show an unequal distribution of body mass, with the front limbs receiving higher peak vertical forces (Meijer et al., 2014). As such, the greater left-right symmetry of the front legs could play an important role in maintaining the overall balance of the animal while walking.

\section{Conclusion}

Normalization of the gait data is suggested as a method to distinguish neuromotor maturation from size effects and postural changes. Aside from the first hour, voluntary locomotion is dynamically similar during early gait development in piglets. As for interlimb coordination, this does not change at all during early gait development, implying this aspect of gait is innate for piglets. Intralimb coordination shows a very fast maturation process, as indicated by rapidly achieved steady values for swing and stance duration, as well as step length. The variability of the gait pattern, indicated by left-right asymmetry, decreases with age and leads to a stable gait pattern within $8 \mathrm{~h}$ of birth. This shows that coordinated movement patterns in pigs are not entirely innate, but that a rapid neuromotor maturation, potentially also the result of the rearrangement or recombination of existing motor modules, takes place in these precocial animals.

\section{Acknowledgements}

The authors would thank Jan Collogne, Jan Van Steelandt and Annelies Ooms from AVEVE (Neerhespen) for providing the piglets and for allowing us to use their accommodation during the experiments. The authors would also wish to thank Gunther Vrolix, Denise Vogel and Seppe Declercq for helping with the experiments and Sam Van Wassenbergh for sharing his expertise on video editing. This paper was greatly improved by the comments of the referees.

\section{Competing interests}

The authors declare no competing or financial interests.

\section{Author contributions}

Conceptualization: C.V.H., P.A., C.V.G.; Methodology: C.V.H., P.A., C.V.G.; Software: J.G.; Formal analysis: C.V.H., E.F.; Investigation: C.V.H., S.P.; Resources: P.A., C.V.G.; Writing - original draft: C.V.H.; Writing - review \& editing: C.V.H., J.G., S.P., E.F., M.A., S.V., P.A., C.V.G.; Visualization: C.V.H.; Supervision: P.A., C.V.G.; Project administration: P.A., C.V.G.; Funding acquisition: P.A., C.V.G.

\section{Funding}

This work was supported by a special research fund of the Universiteit Antwerpen (grant number GOA-33927).

\section{Supplementary information}

Supplementary information available online at

http://jeb.biologists.org/lookup/doi/10.1242/jeb.157693.supplemental

\section{References}

Abourachid, A. (2003). A new way of analysing symmetrical and asymmetrical gaits in quadrupeds. C. R. Biol. 326, 625-630.

Abourachid, A., Herbin, M., Hackert, R., Maes, L. and Martin, V. (2007). Experimental study of coordination patterns during unsteady locomotion in mammals. J. Exp. Biol. 210, 366-372.
Aerts, P., Van Damme, R., Van Elsacker, L. and Duchêne, V. (2000). Spatiotemporal gait characteristics of the hind-limb cycles during voluntary bipedal and quadrupedal walking in bonobos (Pan paniscus). Am. J. Phys. Anthropol. 111, 503 Alexander, R. (1992b). Basic Mechanics. Berlin: Springer Verlag.

Alexander, R. M. (1977). Mechanics and scaling of terrestrial locomotion. In Scale Effects in Animal Locomotion (ed. T. J. Pedley). New York: Academic Press.

Alexander, R. M. (2003). Principles of Animal Locomotion. Princeton University Press.

Alexander, R. M. N. and Jayes, A. S. (1983). A dynamic similarity hypothesis for the gaits of quadrupedal mammals. J. Zool. 201, 135-152.

Arellano, C. J. and Kram, R. (2014). Partitioning the metabolic cost of human running: a task-by-task approach. Integr. Comp. Biol. 54, 1084-1098.

Back, W., Barneveld, A., Schamhardt, H., Bruin, G. and Hartman, W. (1994). Longitudinal development of the kinematics of 4-, 10-, 18-and 26-month-old Dutch Warmblood horses. Equine Vet. J. 26, 3-6.

Bertram, J. E. A. (ed.) (2016). Understanding Mammalian Locomotion: Concepts and Applications. Hoboken, NJ: John Wiley \& Sons.

Besancon, M. F., Conzemius, M. G., Evans, R. B. and Ritter, M. J. (2004). Distribution of vertical forces in the pads of greyhounds and labrador retrievers during walking. Am. J. Vet. Res. 65, 1497-1501.

Biewener, A. A. (2003). Animal Locomotion. Oxford: Oxford University Press.

Bolles, R. C. and Woods, P. J. (1964). The ontogeny of behaviour in the albino rat. Anim. Behav. 12, 427-441.

Budsberg, S. C., Verstraete, M. C. and Soutas-Little, R. W. (1987). Force plate analysis of the walking gait in healthy dogs. Am. J. Vet Res. 48, 915-918.

Cappellini, G., Ivanenko, Y. P., Poppele, R. E. and Lacquaniti, F. (2006). Motor patterns in human walking and running. J. Neurophysiol. 95, 3426-3437.

Clarke, K. and Still, J. (1999). Gait analysis in the mouse. Physiol. Behav. 66, 723-729.

Clarke, K. and Still, J. (2001). Development and consistency of gait in the mouse. Physiol. Behav. 73, 159-164.

Crowe, A., Samson, M. M., Hoitsma, M. J. and Van Ginkel, A. A. (1996). The influence of walking speed on parameters of gait symmetry determined from ground reaction forces. Hum. Mov. Sci. 15, 347-367.

Dominici, N., Ivanenko, Y. P., Cappellini, G., D’avella, A., Mondì, V., Cicchese, M., Fabiano, A., Silei, T., Di Paolo, A. and Giannini, C. (2011). Locomotor primitives in newborn babies and their development. Science 334, 997-999.

Duberstein, K. J., Platt, S. R., Holmes, S. P., Dove, C. R., Howerth, E. W., Kent M., Stice, S. L., Hill, W. D., Hess, D. C. and West, F. D. (2014). Gait analysis in a pre-and post-ischemic stroke biomedical pig model. Physiol. Behav. 125, 8-16.

Estes, R. D. and Estes, R. K. (1979). The birth and survival of wildebeest calves. Z. Tierpsychol. 50, 45-95.

Fung, J. and Macpherson, J. M. (1995). Determinants of postural orientation in quadrupedal stance. J. Neurosci. 15, 1121-1131.

Garwicz, M., Christensson, M. and Psouni, E. (2009). A unifying model for timing of walking onset in humans and other mammals. Proc. Natl Acad. Sci. USA 106 21889-21893.

Graves, H. B. (1984). Behavior and ecology of wild and feral swine (Sus scrofa). J. Anim. Sci. 58, 482-492.

Grillner, S. (2011). Control of locomotion in bipeds, tetrapods, and fish. Comp. Physiol.

Grillner, S., Cangiano, L., Hu, G.-Y., Thompson, R., Hill, R. and Wallén, P. (2000). The intrinsic function of a motor system - from ion channels to networks and behavior. Brain Res. 886, 224-236

Herzog, W., Nigg, B. M., Read, L. J. and Olsson, E. (1989). Asymmetries in ground reaction force patterns in normal human gait. Med. Sci. Sports Exerc. 21, 110-114. Hof, A. L. (1996). Scaling gait data to body size. Gait Posture 3, 222-223.

Ivanenko, Y. P., Dominici, N., Cappellini, G., Dan, B., Cheron, G. and Lacquaniti, F. (2004a). Development of pendulum mechanism and kinematic coordination from the first unsupported steps in toddlers. J. Exp. Biol. 207, 3797-3810.

Ivanenko, Y. P., Poppele, R. E. and Lacquaniti, F. (2004b). Five basic muscle activation patterns account for muscle activity during human locomotion. J. Physiol. 556, 267-282.

Ivanenko, Y. P., Dominici, N., Cappellini, G. and Lacquaniti, F. (2005) Kinematics in newly walking toddlers does not depend upon postural stability. J. Neurophysiol. 94, 754-763.

Ivanenko, Y. P., Poppele, R. E. and Lacquaniti, F. (2006). Motor control programs and walking. Neuroscientist 12, 339-348.

Jeleń, P., Wit, A., Dudziński, K. and Nolan, L. (2008). Expressing gait-line symmetry in able-bodied gait. Dyn. Med. 7, 1

Kano, W. T., Rahal, S. C., Agostinho, F. S., Mesquita, L. R., Santos, R. R., Monteiro, F. O., Castilho, M. S. and Melchert, A. (2016). Kinetic and temporospatial gait parameters in a heterogeneous group of dogs. BMC Vet Res. 12, 1

Kim, J. and Breur, G. J. (2008). Temporospatial and kinetic characteristics of sheep walking on a pressure sensing walkway. Can. J. Vet. Res. 72, 50

Lacquaniti, F., Ivanenko, Y. P. and Zago, M. (2012a). Development of human locomotion. Curr. Opin. Neurobiol. 22, 822-828.

Lacquaniti, F., Ivanenko, Y. P. and Zago, M. (2012b). Patterned control of human locomotion. J. Physiol. 590, 2189-2199. 
Latash, M. L. (2008). Neurophysiological Basis of Movement. Champaign, IL: Human Kinetics.

Le Dividich, J., Rooke, J. and Herpin, P. (2005). Nutritional and immunological importance of colostrum for the new-born pig. J. Agr. Sci. 143, 469-485.

Liu, M., He, P., Aherne, F. and Berg, R. (1999). Postnatal limb bone growth in relation to live weight in pigs from birth to 84 days of age. J. Anim. Sci. 77 1693-1701.

Marsh, R. L., Ellerby, D. J., Carr, J. A., Henry, H. T. and Buchanan, C. I. (2004) Partitioning the energetics of walking and running: swinging the limbs is expensive. Science 303, 80-83.

Meijer, E., Bertholle, C. P., Oosterlinck, M., Van Der Staay, F. J., Back, W. and Van Nes, A. (2014). Pressure mat analysis of the longitudinal development of pig locomotion in growing pigs after weaning. BMC Vet. Res. 10, 1.

Neptune, R. R., Clark, D. J. and Kautz, S. A. (2009). Modular control of human walking: a simulation study. J. Biomech. 42, 1282-1287.

Nishikawa, K., Biewener, A. A., Aerts, P., Ahn, A. N., Chiel, H. J., Daley, M. A., Daniel, T. L., Full, R. J., Hale, M. E. and Hedrick, T. L. (2007). Neuromechanics: an integrative approach for understanding motor control. Integr. Comp. Biol. 47 16-54.

Noblet, J., Dourmad, J., Etienne, M. and Le Dividich, J. (1997). Energy metabolism in pregnant sows and newborn pigs. J. Anim. Sci. 75, 2708-2714.

Oosterlinck, M., Pille, F., Back, W., Dewulf, J. and Gasthuys, F. (2010). Use of a stand-alone pressure plate for the objective evaluation of forelimb symmetry in sound ponies at walk and trot. Vet. J. 183, 305-309.

Orlovsky, G., Deliagina, T. and Grillner, S. (1999). Neural Control of Locomotion New York: Oxford UP.

Pearson, K. (1976). The control of walking. Sci. Am. 235, 72-86.

Pennycuick, C. (1975). On the running of the gnu (Connochaetes taurinus) and other animals. J. Exp. Biol. 63, 775-799.

Pond, W. G. and Mersmann, H. J. (2001). Biology of the Domestic Pig. Ithaca, NY: Comstock Pub. Associates, Cornell University Press.

Quiniou, N., Dagorn, J. and Gaudré, D. (2002). Variation of piglets' birth weight and consequences on subsequent performance. Livest. Prod. Sci. 78, 63-70.
Randall, G. (1971). The relationship of arterial blood pH and pCO2 to the viability of the newborn piglet. Can. J. Comp. Med. 35, 141

Robinson, R., Herzog, W. and Nigg, B. (1987). Use of force platform variables to quantify the effects of chiropractic manipulation on gait symmetry. J. Manipulative Physiol. Ther. 10, 172-176.

Segers, V., Aerts, P., Lenoir, M. and De Clercq, D. (2006). Spatiotemporal characteristics of the walk-to-run and run-to-walk transition when gradually changing speed. Gait Posture 24, 247-254.

Stavrakakis, S., Guy, J., Warlow, O., Johnson, G. and Edwards, S. (2014). Longitudinal gait development and variability of growing pigs reared on three different floor types. Animal 8, 338-346.

Sutherland, D. (1997). The development of mature gait. Gait Posture 6, 163-170.

Theil, P., Cordero, G., Henckel, P., Puggaard, L., Oksbjerg, N. and Sørensen, M. (2011). Effects of gestation and transition diets, piglet birth weight, and fasting time on depletion of glycogen pools in liver and 3 muscles of newborn piglets. J. Anim. Sci. 89, 1805-1816.

Theil, P. K., Lauridsen, C. and Quesnel, H. (2014). Neonatal piglet survival: impact of sow nutrition around parturition on fetal glycogen deposition and production and composition of colostrum and transient milk. Animal 8, 1021-1030.

Thorup, V. M., Tøgersen, F. A., Jørgensen, B. and Jensen, B. R. (2007) Biomechanical gait analysis of pigs walking on solid concrete floor. Animal 1 708-715.

Tuchscherer, M., Puppe, B., Tuchscherer, A. and Tiemann, U. (2000). Early identification of neonates at risk: traits of newborn piglets with respect to survival. Theriogenology 54, 371-388.

Verdugo, M. R., Rahal, S. C., Agostinho, F. S., Govoni, V. M., Mamprim, M. J. and Monteiro, F. O. (2013). Kinetic and temporospatial parameters in male and female cats walking over a pressure sensing walkway. BMC Vet. Res. 9, 1.

Von Wachenfelt, H., Pinzke, S., Nilsson, C., Olsson, O. and Ehlorsson, C.-J. (2008). Gait analysis of unprovoked pig gait on clean and fouled concrete surfaces. Biosyst. Eng. 101, 376-382.

Zaleski, H. M. and Hacker, R. R. (1993). Variables related to the progress of parturition and probability of stillbirth in swine. Can. Vet. J. 34, 109. 